\title{
Why people adopt VR English language learning systems: An extended perspective of task-technology fit
}

\author{
Yi-Ting Wang \\ Ling Tung University \\ yw7yw7k@gmail.com
}

\author{
Travis K. Huang \\ Ling Tung University \\ travisk.huang@gmail.com
}

\author{
Kuan-Yu Lin \\ Ling Tung University \\ ntustmislab@gmail.com
}

\begin{abstract}
Virtual Reality (VR) techniques involving immersion, interaction, and imagination, not only can improve conventional teaching methods, but also can enhance the transmission of education training contents through the interaction and simulation characteristics of VR. Incorporating information technology (IT) with English teaching has become an important issue in the academic field. Emerging after computer-assisted teaching, interactive network learning, distance education, and mobile learning in the early days, virtual reality techniques have been regarded as a new trend of merging technology with education.

To explore the factors affecting users' adoption intention of VR English language learning systems (VRELLS), this study has sought to build a theoretical framework based on the task-technology fit theory (extrinsic motivation) combining users' needs (internal and external needs) and satisfaction to put forward an integrated research model (perceived needstechnology fit model), which explicates people's adoption behaviors of VRELLS. An online questionnaire was employed to collect empirical data. A total of 291 samples were analyzed using a structural equation modeling (SEM) approach. The results of the study showed that both perceived needstechnology fit and satisfaction play a significant role in the user' adoption intention of VRELLS services. In addition, the utilitarian and hedonic needs have a positive impact on the user's perceived needstechnology fit. Also, it was found that relative advantage, service compatibility and complexity are important factors in influencing individuals' perceived needs-technology fit. The implications of these findings are discussed along with suggestions for future research.
\end{abstract}

\section{Introduction}

E-learning involves the transmission and use of teaching contents or learning experience via IT. In other words, learners can access instructions of experts or lecturers through online and computer-assisted learning environments and mechanisms, without the constraints of time and place, and further promote the acquisition, dissemination, preservation and management of knowledge within the organization [1] [2].

With the development of IT and the maturity of the network communication infrastructure, people's lives are gradually loaded with a wide variety of multimedia. In addition to the appearance and functional satisfaction, consumers are also pursuing IT, like VR that can be personally experienced. Over the past years, VR has been widely used in the entertainment industry. However, with the maturity of technology and cost reduction, VR technology is no longer limited by related devices, such as visual helmets, mainframe efficacy, equipment expenditures, etc. Many companies apply VR to education, medicine, construction, manufacturing, tourism, retail industries and other fields. Among them, education application has especially a great potential in breaking the limitations of traditional teaching environments and allows learners to simulate, experience, and drill the process. By transforming abstract knowledge concepts into concrete experience, and providing better efficiency in knowledge acquiring, VR enables learners to achieve better learning outcomes in terms of the acquisition, preservation and management of knowledge, thereby increasing their willingness to learn [3][4].

In the teaching context, VR can be used to design various practical situations [5] [6] and provide a sense of presence, fun, immersion, exploration, dynamic interaction, and instant visual feedback [3][4]. In addition, learners can explore more and teaching can be differentiated so as to create a student-centered learning environment [3][4]. Yang et al. [7] pointed out that leading the students directly into an environment of English thinking mode is the best way to achieve English learning mental state. In other words, what they have acquired from the learning process tends to last longer if vivid scenes and real-time interaction with the figures are provided for students to have a sense of immersion. Therefore, it is important to VR 
service providers to understand what factors can influence learners' willingness to use VR, so that they can better their designs to grasp learners' attention. This is one of the important issues this study aims to explore.

In recent research on IT use behavior, the tasktechnology fit theory [8] has been widely used to explore various emerging science and technology research tasks, such as online teaching courses, online banking, mobile banking, smart watches, e-libraries, and e-books [4][9][10] [11][12]. A body of research shows that users, in adopting an emerging IT, are often limited by the balance between IT (technical characteristics) and self-ability which leads to the goal (task) of the rationality and the behavior of adoption. Based on the theory of task-technology fit, Kwai Fun Ip and Wagner [13] proposed that the use of information technology should be discussed from the compatibility of user needs and IT characteristics.

Based on the above, the research on users' behavior towards emerging technologies is often discussed with the theory of task-technology fit, and the task characteristics (extrinsic motivation) and technological characteristics are used as factors influencing the degree of adaptation. However, this study argues that in the use of emerging IT, like VR, to help users in learning, user's intrinsic demand motivation characteristics, in addition to the consideration of task characteristic, should also be taken into consideration. Thus, by understanding whether users' internal and external motivation needs and the technology's services (technical characteristics) can meet their needs (fit), learner satisfaction and usage behavior can be enhanced. Therefore, this study, based on the theory of task-technology fit (extrinsic motivation) combining the technological characteristics, users' needs (intrinsic extrinsic motivation) and satisfaction proposed by scholars [13] [14] [15], has sought to develop a "perceived needs-technology fit model" and to explore the factors that influence users' adoption behaviors in the VR English language learning system.

\section{Literature review}

\subsection{Application of VR in Education}

Following computer-assisted instruction, interactive online learning, distance learning, and mobile learning in early stage, VR technology is now regarded as a new wave of application trends in technology integration of education. This is mainly because of the characteristics of integration, interactivity and imagination that VR technology possesses. These characteristics not only reduce the limitations of traditional learning methods, but also enhance the communication of educational training content through the interaction and simulation features of VR [5]. Manufacturers of wearable devices and VR content providers have been investing in education applications. For example, Oculus, a USbased company, has released its first head-mounted display, Oculus Rift, in addition to the World of Comenius experimental project. Oculus Rift DK2 head-mounted display and Leap Motion sensor, in collaboration with the Czech Mendel Grammar School, allow students to experience anatomy and biology courses, such as the human body, bone composition, organ structure, and observation of blood flow, etc. To bring the VR headset into the mass market, Google launched Cardboard, a carton-style VR product in 2014, and the "Expedition Pioneer Program campus experience program in September 2015, to help teachers and students around the world experience the immersive feeling of VR technology.

Unimersi, an online teaching platform content provider, offers a wide range of VR teaching contents covering science, history, geography and many other subjects. Learners are required to be equipped with VR head-mounted displays, such as Oculus Rift, Google Cardboard, HTC VIVE, and Samsung Gear Headsets, to explore the Milky Way on a space shuttle, the mysterious Stonehenge, and stroll in Roman Colosseum. Targeting universities, research institutes, and corporate occupational training courses, Immersive VR Education, an Ireland-based startup, created a platform called "Engage", to provide an easy and interesting visual alternative for students to understand any subject content that is hard to digest.

\subsection{Task-Technology Fit Theory}

In recent years, much research on the user behavior of emerging technologies adopted the task-technology fit (TTF) theory of external motivation view. Specifically, many studies based on this theory have extended to develop various research models [4][9][11][13].

Goodhue and Thompson [16] suggested that technology can only be adopted when its functionality meets the needs of the task. Therefore, they proposed the task-technology fit model to further explore the relationship between individuals, tasks, and technology. In other words, when the task and technology are fit, users' performance can be strengthened. From the perspective of user recognition, TTF emphasizes the fit of task characteristics and technological characteristics were the most important factors that would directly affect the willingness and effectiveness of IT and the performance of individual tasks.

In the past, TTF was mostly used to explore the performance of the company's internal information system, focusing mainly on the discussion of task characteristics of the employees and the characteristics of the IS. Therefore, the application of the TTF 
framework to other fields and the individual subjects is scarce in literature. However, in recent years, many scholars [4][10][12] have tried to include intention to adopt wearable devices [10], students' use behavior in adopting virtual learning systems [14], and user learning behaviors towards virtual reality [4]. Studies have shown that the degree of fit between tasks, technology, and users is an important factor affecting the individual adoption of information systems.

However, Kwai Fun IP and Wagner [13] further suggested that the adoption behavior of IT by users should be explored from the perspective of fit between users' needs (intrinsic motivation) and IT characteristics, and proposed needs-technology fit model. At the same time, Lin [14] assumed that users' perceived fitness towards the virtual learning system would have an impact on satisfaction, continued use and positive learning effect. Lin [15] explored people's intention to use mobile technology and the results indicated that motivational needs and technological characteristics would have a direct impact on users' perceived needs-technology fit towards mobile technology, and thus affect their satisfaction and continued use.

Previous research [13][15] has found that people tend to be conscious of their needs and try to fulfill their motivation by choosing the appropriate media. According to the cognitive evaluation theory, the human incentive system has two sub-systems: internal and external [17][18]. Extrinsic motivation is about a specific goal achieved through an activity [19], while intrinsic motivation is the willingness to continuously participate in an activity without receiving any external rewards [15]. Both extrinsic motivation (utilitarian) and intrinsic motivation (hedonic) have been found to have an influence on users' attitudes toward IT [15]. Many studies [15] [20] indicated that apart from usefulness requirements, feelings of entertainment demand are also one of the factors affecting how and why users adopt a certain IT.

To identify the antecedents of technology characteristics of creation, this study adopts Rogers' [21] perspective of perceived characteristics of innovations (PCI). Rogers [21] pointed out that relative advantage, compatibility, complexity, observability, and trialability are important characteristics that influence an individual's perception of new technology. Therefore, this study will use these five characteristics as part of the technical characteristics of the VR learning system.

This study extends the research model based on the TTF theory and explores the intention of users to adopt the VR English language learning system. This study argues that the VR English learning system requires not only to meet users' needs (intrinsic and extrinsic motivation) but also to reach the degree of fit between technical characteristics and users' motivational needs to enhance user satisfaction and attract users' adoption behaviors.

\section{Research model and hypotheses}

Figure 1 illustrates the proposed model, which is based on the TTF and related literature. The definition and hypothesis of each construct of the model are explicated in the following subsections.

3.1. Perceived needs-technology fit

As defined by Goodhue and Thompson [15], tasktechnology fit is the degree to which IT assists individuals in completing tasks or combination of tasks. In other words, IT will only be used when its functions meet or render the required support to users' task activities. Goodhue [22] pointed out that users' task needs have three constructs: information identification, information acquisition, information integration, and interpretation. The IS must be able to support users' task requirements. The technical characteristics refer to the tools used by individuals to complete their tasks [16]. This means that technology is a computer- related backup service for users to complete the tasks. Therefore, VR that meets users' needs is considered to have achieved the task (demand)-technology fit. This study maintains that users can view scenes from multiple angles, have immersive experience [23], and make English learning interaction with characters with the assistance of VR panorama technology as if in the real world, to satisfy their knowledge learning needs, to improve satisfaction, and thus increase their willingness to adopt the technology.

Kwai Fun IP and Wagner [13] contended that users' needs-technology fit is one of the main factors affecting the IT adoption. The study found that needstechnology fit tends to promote users' behavior. On the other hand, Lin [14], by constructing a research structure from the task-technology fit theory, has found that users' perceived VR learning system has a positive effect on their satisfaction, which further affects the willingness to use. Lin [15] found that users' perceived needs-technology fits have a significant impact on the satisfaction and use behavior of mobile technology systems. Therefore, this study considers that when users' needs fit with the technological features of VR English learning systems, users' intention to adopt and satisfaction will be obtained. This study therefore proposes the following hypothesis:

[H1] Perceived needs-technology fit positively affects users' intention to adopt VRELLS.

[H2] Perceived needs-technology fit positively affects positively affects user satisfaction. 


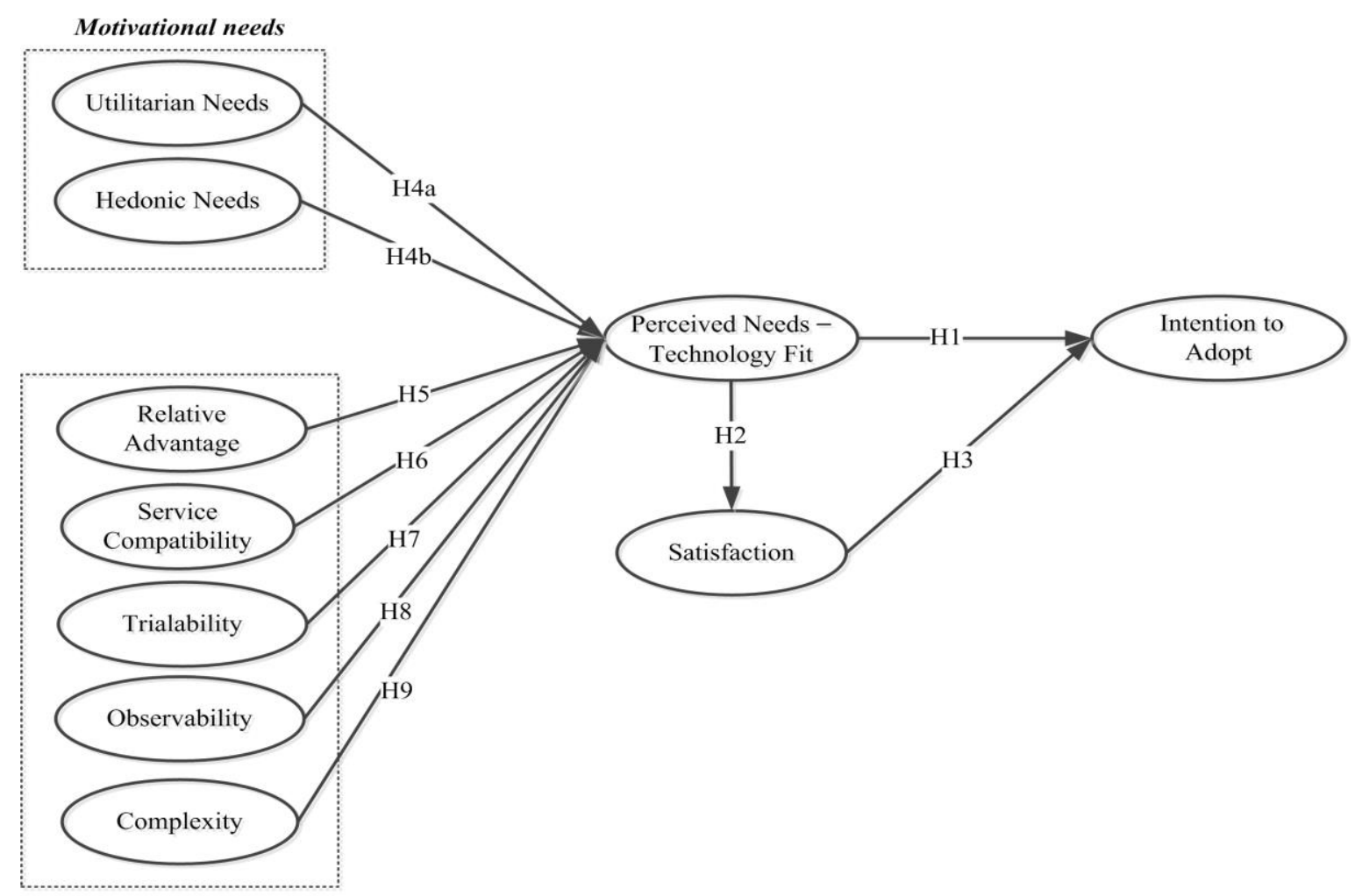

Technology characteristics

Figure 1. The research model

\subsection{User satisfaction and intention to adopt VRELLS}

Scholars [24][25] defined satisfaction as users' perceived fulfillment of quality and performance compared to the original expectations towards the product or service. In other words, when a customer has used a product or service, satisfaction will be generated if the quality or performance of the perceived product or service meets or exceeds what was expected.

Many scholars [14][15][26][27] pointed out that user satisfaction has a strong influence on users' behavior. According to the combined opinions of scholars, this study maintains that in the context of the VR English learning system, user satisfaction with the VR English learning system will affect their intention to adopt. Thus, this study assumes:

[H3] User satisfaction positively affects uses' intention to adopt VRELLS.

\subsection{Motivational needs (Utilitarian needs and Hedonic needs)}

Lin et al. [18] pointed out that IT application to the learning environment requires not only the consideration of the user's knowledge acquisition needs, but also the aspect of entertainment needs.

Utilitarian needs mean the rational goal-oriented purpose for the individual's adoption of IT [15]. Therefore, this study infers that when a user thinks that his/her learning goals, such as the efficiency of knowledge acquisition and instant obtaining of learning information, can be achieved through VR, the motivation for selecting the technology channel will be improved.

The hedonic needs refer to the reasonable purpose and positive emotions [15] of the adopted IT. Many scholars [4][6][28] found that VR-assisted language learning enables users to experience features not previously available on the websites, such as a sense of presence, fun, and instant visual feedback, which allows learners to enjoy a pleasant experience, thereby enhancing their positive feelings.

Kwai Fun IP and Wagner's [13] studies suggested that users' needs will affect their perceived IT needstechnology fit. Lin [15] explored the usage behavior of mobile technology, and the results showed that both utilitarian and hedonic needs would respectively have a direct effect on users' perceived needs-technology fit. 
Integrating various views of the afore-mentioned scholars, this study proposes the following hypothesis:

[H4a] Utilitarian needs positively affect users' intention to adopt VRELLS.

[H4b] Hedonic needs positively affect users' intention to adopt VRELLS.

3.4. Technology characteristics (relative advantage, service compatibility, trialability, observability, and complexity)

\section{Relative advantage}

Rogers [21] defined relative advantage as whether a new product or service has some better attributes or benefits. In other words, if the user believes that the new product or service has a higher relative benefit than the existing one, he/she will consider the new product or service having relative advantage [29].

Previous literature on VR education applications has found that researchers used to adopt VR as a teaching tool to implement curriculum contents of higher abstract or practical nature [3][4][7]. This was mainly because of the three characteristics of integration, interactivity and imagination of VR which allow learners to interact through peripherals in simulated situations as if in real life. VR-assisted language learning provides a sense of presence, fun, exploration, dynamic interactivity, and instant visual feedback [4][6][28]. VR technology provides users with English learning assistance, real feeling, and a complete knowledge learning experience. Therefore, this study argues that VR technology can bring feelings that are better than the old technology to the users, and can enhance the perceived needs-technology fit for the system, and further promote users' usage behavior. Therefore, this study proposes the following hypothesis:

[H5] Relative advantage positively affects users' perceived needs-technology fit.

\section{Service compatibility}

In his innovation construct, Rogers [21] defined compatibility as the degree to which innovations are consistent with existing adopters' values, past experiences, and needs. Service compatibility emphasizes the fitness of services provided by IT with the needs of users [15][29]. The integration of VR technology into teaching not only improves the limitations of conventional learning methods, but also enhances learning content training and message transmission through the interaction and immersive nature of VR [6]. In other words, when users perceive they can engage in real-world learning situations through the VR service and interact with the characters in the situation, as they used to have in the conventional teaching mode, to meet their perceptual needs, their feeling of technology and satisfaction can be enhanced, which in turn will affect their usage behavior. Therefore, we propose the following hypothesis:

[H6] Service compatibility positively affects users' perceived needs-technology fit.

\section{Trialability}

Trialability is defined as an individual's ability to use the service or technology to gain operational experience when using an innovative technology or service. Many studies [30][31][32] pointed out that trialability affects users' intention to adopt a technology service or product. In other words, trialability can affect users' beliefs and thus affects their intention to adopt IT.

Emerging technologies are subject to users' willingness to try - users are required to operate the system in order to obtain experience. To VR users, VR technology in education application is still a relatively new technology. Because the adoption of VR devices (such as Mobile VR, PC VR, and Standalone VR) requires a certain amount of expenditure, this results in lower acceptance of VR. Therefore, more and more enterprises have recently introduced VR technology into web applications. WebVR enables users to operate on mobile vehicle devices, personal computers and VR devices. General mobile vehicle or a PC's capacity to preview the 360 panorama scenes without a display helmet has increased users' chance of trialability. Hence this study contends that when users try to use VR, it can effectively improve their demand for the VR English learning systems - the degree of technology fit. Therefore, we propose the following hypotheses:

[H7] Trialability positively affects users' perceived needs-technology fit.

\section{Observability}

Observability refers to the use of technology or service by an individual when he or she observes others using an innovative technology or service. Dong et al. [33] explored online community business research and defined visibility as individuals seeing others using technology products or technology services to obtain information. Research findings have shown that visibility reduces individual perceived risks [33] and thus influences use behavior. Johnson et al. [34] believed that when users see other people using emerging technologies, if the system meets the requirements, it will affect their intention to adopt. 
In the past, VR was constrained to matters, such as price, equipment discomfort, and equipment specifications, which had limited VR integration into people's lives. However, with the maturity of technology and cost reduction, VR technology has become powerful in educational applications. That is, by driving more and more manufacturers to develop virtual reality teaching content, providing more users to preview and use the service, to improve the way VR services penetrate people's learning, and let more users experience the course of learning through this technology channel. Therefore, this study maintains that when the observability of VR English learning systems is higher, users will have a higher degree of needs-technology fit. Therefore, we propose the following hypothesis:

[H8] Observability positively affects users' perceived needs-technology fit.

\section{Complexity}

Complexity requires individuals to spend much time or efforts in learning an innovative technology or service [29] [34]. In other words, a product or service is relatively difficult to understand and use. Complexity is widely used to explore the use of emerging technology services or products. With respect to emerging products or services, if the system interface is difficult to operate, user satisfaction with the product will be reduced, and the impression of the product or service will be negative. Thus, the difficulty of operating IS will result in a negative impact, which will affect users' reluctance to adopt emerging IT. Therefore, this study contends that when uers use VR English learning platforms for system operation, if they need to access multiple interfaces or operations to use the service, then it will affect the user's perception of the system - the feeling of technology fit, and thus the usage behavior.

[H9] Complexity negatively affects users' perceived needs-technology fit.

\section{Measurement}

The questionnaires were adapted from relevant prior research and modified to reflect the characteristics of the VRELLS. The research model includes ten constructs. Each construct was measured with multiple items. The items of adoption intention (four items) were modified from Kim and Ammeter [35]. Measures of perceived needs-technology fit (four items) were adapted from Lin [15]. Measures of user satisfaction were adapted from Lee [36]. Items addressing utilitarian needs (three items) and hedonic needs (three items) were modified from Alalwan [37] and Lin [15]. Relative advantage (two items) was assessed based on the scale proposed by Fang et al. [38]. Service compatibility (three items) was adapted from Fang et al. [38] and Lin and Lu [29]. Items for measuring trialability (four items) and observability (four items) were developed from Johnson et al. [34]. Finally, items measuring complexity (three items) were adapted from Fang et al. [38] and Kim and Ammeter [35]. All items were measured on a 5-point Likert-type scale, ranging from "strongly disagree" (1) to "strongly agree" (5).

\section{Results}

\subsection{Data collection and sampling}

Targeting Taiwanese users who were using or had used VR English language learning systems, we explored VR applications, including mobile VR, PC VR, standalone VR, and web VR users. The invitation messages were posted on forums associated with VR English language learning sites. To prevent replicate entries, respondent identities were confirmed by e-mail and IP addresses when the questionnaires were received. We finally obtained 291 valid responses from the online surveys. The valid responses included 121 females (41.6\%) and $170(58.4 \%)$ males. The majority $(45.9 \%)$ were aged between 19 and $25 ; 27.7 \%$ were aged between 26 and 35, 18.2\% were under 18, and $8.2 \%$ were aged 36 and over.

\subsection{Tests of the measurement assessment}

To confirm the adequacy of the measurement model, reliability and construct validity were considered. Reliability was measured using the composite reliability (CR) to evaluate internal consistency. As shown in Table 1, all CR values for all constructs were above the recommended level of 0.70 , indicating adequate internal consistency [39][40].

In terms of convergent validity, Fornell and Larcker [39] proposed when each measurement item correlates strongly with its assumed theoretical construct. It can be examined by using the $\mathrm{CR}$ and the average variance extracted (AVE). The measurement standards: (1) CR should exceed 0.7, and (2) the average variance extracted (AVE) of each dimension should exceed 0.5. As shown in Table 1, CR of constructs ranged from 0.75 to 0.94 and AVE ranged from 0.52 to 0.85 . Therefore, the measurement model featured adequate reliability and convergent validity. 
Table 1. Construct reliability, convergent validity, and discriminant validity coefficients.

\begin{tabular}{|c|c|c|c|c|c|c|c|c|c|c|c|c|c|c|}
\hline \multirow[t]{2}{*}{ Construct } & \multirow[t]{2}{*}{$\mathrm{CR}$} & \multirow[t]{2}{*}{ AVE } & \multirow[t]{2}{*}{ Mean } & \multirow[t]{2}{*}{ SD } & \multicolumn{10}{|c|}{ AVE and squared correlations } \\
\hline & & & & & UN & HN & RA & $\mathrm{SC}$ & TA & $\mathrm{OB}$ & $\mathrm{CP}$ & PNTF & SA & ITA \\
\hline UN & 0.83 & 0.61 & 3.84 & 0.50 & 0.78 & & & & & & & & & \\
\hline $\mathrm{HN}$ & 0.81 & 0.58 & 3.87 & 0.49 & 0.41 & 0.76 & & & & & & & & \\
\hline RA & 0.75 & 0.60 & 3.93 & 0.51 & 0.17 & 0.19 & 0.77 & & & & & & & \\
\hline $\mathrm{SC}$ & 0.78 & 0.54 & 3.90 & 0.43 & 0.22 & 0.21 & 0.45 & 0.73 & & & & & & \\
\hline TA & 0.83 & 0.54 & 3.66 & 0.49 & 0.17 & 0.07 & 0.36 & 0.23 & 0.73 & & & & & \\
\hline OB & 0.81 & 0.52 & 3.73 & 0.43 & 0.16 & 0.21 & 0.33 & 0.36 & 0.34 & 0.72 & & & & \\
\hline $\mathrm{CP}$ & 0.94 & 0.85 & 3.13 & 1.15 & -0.12 & -0.09 & -0.06 & -0.02 & -0.05 & 0.05 & 0.92 & & & \\
\hline PNTF & 0.81 & 0.67 & 3.86 & 0.43 & 0.39 & 0.35 & 0.47 & 0.49 & 0.32 & 0.37 & -0.16 & 0.82 & & \\
\hline SA & 0.85 & 0.66 & 3.89 & 0.48 & 0.28 & 0.28 & 0.22 & 0.17 & 0.14 & 0.12 & -0.13 & 0.40 & 0.81 & \\
\hline ITA & 0.84 & 0.57 & 4.00 & 0.56 & 0.38 & 0.40 & 0.25 & 0.18 & 0.09 & 0.09 & -0.03 & 0.43 & 0.59 & 0.75 \\
\hline
\end{tabular}

Note: Utilitarian needs (UN); Hedonic needs (HN); Relative advantage (RA); Service compatibility (SC); Trialability (TA); Observability (OB); Complexity (CP); Perceived needs-technology fit (PNTF); Satisfaction (SA); Intention to adopt (ITA).Diagonal elements (bold) are the square root of average variance extracted (AVE) between the constructs and their measures. Off-diagonal elements are correlations between constructs. For discriminant validity, diagonal elements (AVE) should be greater than off-diagonal elements.

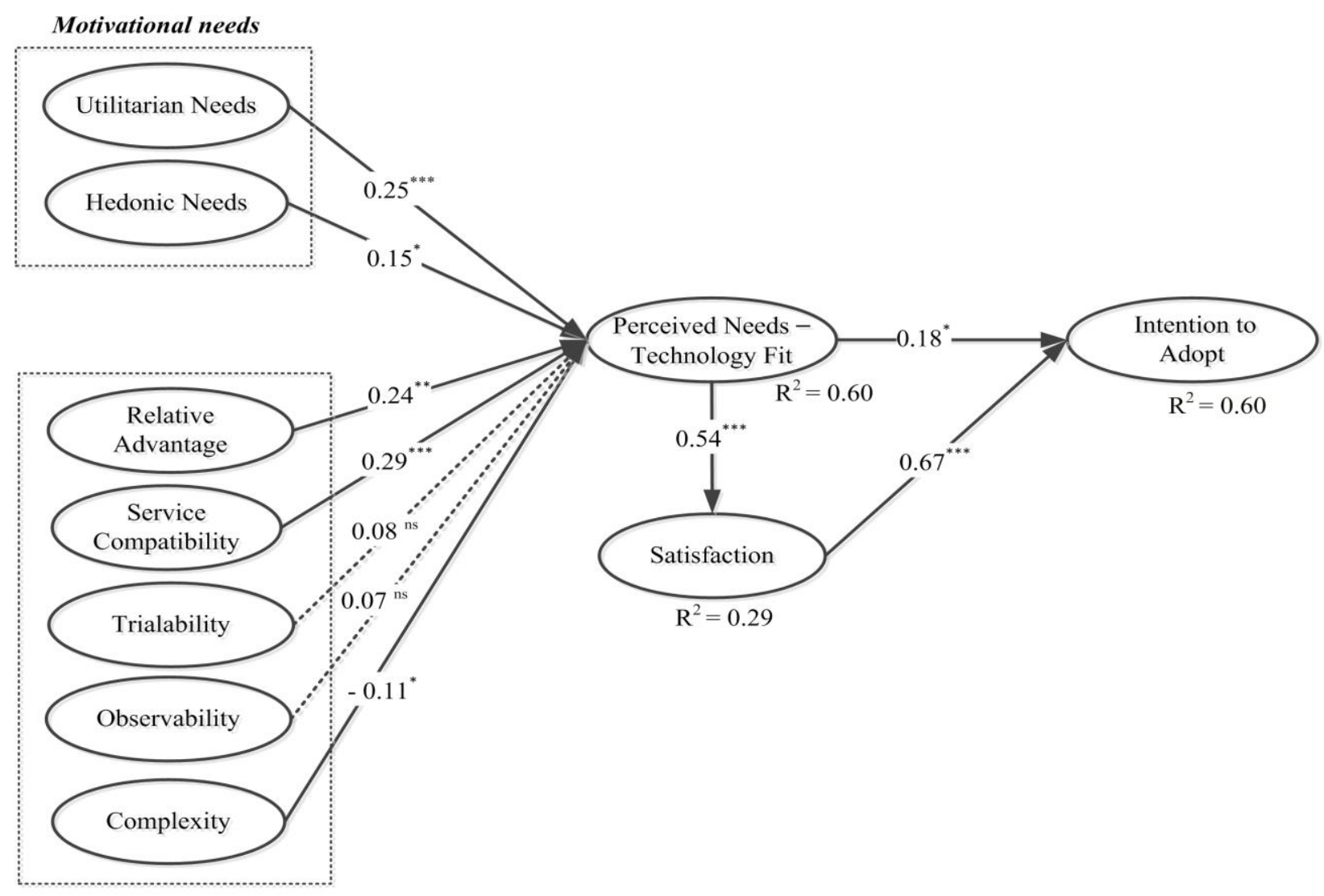

Technology characteristics

Figure 2. Structural model results (Note. ${ }^{* * *} p<0.001,{ }^{* *} p<0.01,{ }^{*} p<0.05$, ns $=$ not significant) 
Discriminant validity was evaluated using a criterion suggested by Fornell and Larcker [39], which states that the square root of the AVE for each construct should exceed the correlation between any pair of distinct constructs. Table 1 presents the matrix of correlation coefficients for all constructs in the current study; the diagonal elements represent the square roots of the AVE for the constructs. The results revealed that the validity was adequate. In summary, our measurement model exhibited satisfactory reliability, convergent validity, and discriminant validity.

\subsection{Tests of the structural model}

We conducted a structural equation modelling analysis using AMOS 21.0 to test the structural model. The model fits criteria suggested by Hayduck [41] $\left(\chi^{2} / \mathrm{df} \leqq 3\right)$, Scott $[42]$ (GFI $\geqq 0.8$ and AGFI $\left.\geqq 0.8\right)$, Hair et al. [43] (NFI $\geqq 0.8$ ), and Bagozzi and Yi [44] (CFI $\geqq 0.9$ and RMSE $\geqq 0.08$ ). The model-fit indices for the structural model indicated a good model fit $(\chi$ $2 / \mathrm{df}=1.558, \mathrm{GFI}=0.87, \mathrm{AGFI}=0.85, \mathrm{NFI}=0.86$, $\mathrm{CFI}=0.95$, and RMSEA $=0.044$ ).

Figure 2 shows the standardized coefficients path, path significances, and variance explained $\left(\mathrm{R}^{2}\right)$ by each path. The results showed that the VR English language learning system adoption intention was predominantly determined by perceived needs-technology fit $(\beta=0.18$, $p<0.05)$ and user satisfaction $(\beta=0.67, p<0.001)$, supporting $\mathrm{H} 1, \mathrm{H} 3$, respectively. Perceived needstechnology fit $(\beta=0.54, p<0.001)$ have significant positive association with user satisfaction thus, $\mathrm{H} 2$ was supported. Utilitarian needs $(\beta=0.25, p<0.001)$, hedonic needs $(\beta=0.15, p<0.05)$, relative advantage $(\beta=0.24, p<0.01)$, and service compatibility $(\beta=$ $0.29, p<0.001$ ) were found to have significant positive association with perceived needs-technology fit. Therefore, H4a, H4b, H5, and H6 were supported. The results also showed that complexity $(\beta=-0.11, p<$ 0.05) was negatively influences perceived needstechnology fit, thus, H9 was supported. In contrast to $\mathrm{H} 7$ and $\mathrm{H} 8$, trialability $(\beta=0.08, p>0.05)$ and observability $(\beta=0.07, p>0.05)$ did not significantly affect perceived needs-technology fit. Most of the hypotheses ( $\mathrm{H} 1, \mathrm{H} 2, \mathrm{H} 3, \mathrm{H} 4 \mathrm{a}, \mathrm{H} 4 \mathrm{~b}, \mathrm{H} 5, \mathrm{H} 6$, and $\mathrm{H} 9)$ were significant in the SEM prediction, except for trialability $(\mathrm{H} 7)$ and observability $(\mathrm{H} 8)$. The variance explained $\left(\mathrm{R}^{2}\right)$ of $\mathrm{VR}$ English language learning systems adoption intention was $60 \%$, that of perceived needs-technology fit was $60 \%$, and that of user satisfaction was $29 \%$.

\section{Discussion and conclusions}

This study focuses on VR users and attempts to examine the reasons why people adopt VR English learning systems from the perspective of perceived needs-technology fit model. The findings are discussed below.

Figure 2 illustrates the research results regarding users. The study found that the main factors that motivate people to use VR are perceived needstechnology fit and satisfaction. Among them, satisfaction has the most significant impact on users' adoption of the VR English learning system. The findings also confirm the views of scholars [14][15][25] that satisfaction plays a very important role in determining people's willingness to adopt IS. People's satisfaction with the IT will positively influence their willingness to act. The results of the study show that if users are satisfied with the VR English learning system, their willingness to adopt will increase, which indicates that the new learning modes, such as the near-reality learning environment, satisfaction of knowledge acquisition, and the instant access to learning information, provided by the VR application to the learning context, can effectively increase the satisfaction of knowledge acquisition during the learning period, and thus the willingness to adopt VR.

Secondly, the effect of the perceived needstechnology fit on user's adoption of the VR English learning system is mainly caused by the characteristics of a sense of presence, fun, immersion, exploration, dynamic interaction and instant visual feedback [4] [23], which allows users to achieve their goals, such as knowledge acquisition efficiency, and instant access to learning information, while enjoying a pleasant experience, and enhances the needs-IT fit. It is obvious that the choice of the technology channel is determined by VR functions offered by the platform. The results of the study are consistent with those of Lin [15] indicating that user satisfaction with mobile technology services is affected by the needs-IT fit, which will further increase their willingness to use. The results of this study also confirm the arguments of Kwai Fun IP and Wagner [13]. Therefore, when providing services, the VR provider should consider the needs-technology fit in order to increase user satisfaction and to attract users' usage behavior.

Since VR is an emerging technology application [2][5][6], for users, the application of VR to education is not only task-oriented but also entertainmentoriented [3][4]. The study found that users' utilitarian and hedonic needs have a direct positive impact on their perceived needs-technology fit. Among them, the utilitarian needs have the most significant impact on users' perceived needs-technology fit. The results are consistent with the research of many scholars [3][4] 
suggesting that teaching through VR technology will facilitate students' learning efficiency (such as knowledge acquisition, preservation and management). As Zhang et al. [4] have shown, through VR technology, learners can more easily conduct selfdirected active learning, which also increases their willingness to learn and thus enhances learning outcomes. That's to say, users can use VR technology to learn as in the real world and interact with the characters in the situation, so that the utilitarian needs of learning are achieved.

In the technical features section, relative advantage, service compatibility, and complexity have a significant impact on user perceived needs- technology fit. First, in the relative advantage, the results, in line with the findings of scholars [14][34], showed that when users think that VR technology is better than conventional technology, when a high relative benefit (such as convenience) is considered, the product or service has relative advantage, will increase or satisfy their needs-technology fit. In the service compatibility aspect, the results are consistent with Lin's [15] findings on the use of mobile technology. When users can engage in the same services as the usual learning mode through VR technology, it will enhance their perceived needs-technology fit. Finally, in the complexity part, the results of the study show that in the process of learning English through VR technology, if the user feels that the overall operation is easy, his/her needs-technology fit will be enhanced. The VR technology industry, therefore, should pay attention to the design of a simple operation interface. If the user thinks that the system is easy to understand, he/she can easily control the services provided by the system, which will minimize the complexity of the VR technology.

\section{Limitations and future research}

As with all research, some intrinsic limitations of this study should be considered. First, based on the theory of task-technology fit (external motivation) and by combining scholars' [13][14] views on characteristics of technology, users' needs (intrinsic and extrinsic motivation) and user satisfaction, this study proposes the perceived needs-technology fit model to explore the reasons behind people's adopting VR English learning systems. Furthermore, we suggest that future studies explore other dependent variables, such as actual usage and learning efficiency. Second, the conclusions were inferred from a single study of samples collected in Taiwan. Therefore, the findings should be generalized cautiously to other VR learning situations. Further research should be conducted in cross-cultural contexts to investigate and compare differences in antecedents of intention to use. Finally, as this study took the approach of a quantitative investigation, the respondents could only respond to the items prescribed in this study; accordingly, a number of users' immediate demands may have been ignored. Hence, we recommend future research incorporate qualitative approaches, including interviews, to show more diversity.

\section{Acknowledgments}

The authors thank the editor and anonymous reviewers for their comments and suggestions. This study was supported by a grant from the Ministry of Science and Technology: project number MOST-1082410-H-275-005-.

\section{References}

[1] Y. H. Tsai, C. H. Lin, J. C. Hong, and K. H. Tai, "The effects of metacognition on online learning interest and continuance to learn with MOOCs", Computers \& Education, 121(1), 2018, pp.18-29.

[2] Y. T. Wang, K. Y. Lin, and Huang, T. K. "Exploring the antecedents of mobile application usage in the context of English learning", the 52nd Hawaii International Conference on System Sciences (HICSS 52), Maui Island, Hawaii, 2019.

[3] P. L. P. Rau, J. Zheng, Z. Guo, and J. Li, "Speed reading on virtual reality and augmented reality", Computers \& Education, 125, 2018, pp. 240-245.

[4] X. Zhang, S. Jiang, P. Ordóñez de Pablos, M.D. Lytras, and Y. Sun, "How virtual reality affects perceived learning effectiveness: a task-technology fit perspective", Behaviour \& Information Technology, 36(5), 2017, pp.548-556.

[5] A. Suh, and J. Prophet. "The state of immersive technology research: A literature analysis", Computers in Human Behavior, 86, 2018, pp.77-90.

[6] D. Sportillo, A. Paljic, and L. Ojeda, "Get ready for automated driving using Virtual Reality", Accident Analysis and Prevention, 118(1), 2018, pp.102-113.

[7] Y. F. Yang, D. C. Wang, and C. S. Hsia, Virtual reality in EFL learning: A study of learning perceptions, motivation, and effectiveness. In Y. N. Leung, M. Jenks, \& C. S. Hsia (Eds.), New Aspect of English Language Learning and Teaching, 413-423. Taipei: Crane Publishing Company Ltd, 2006.

[8] D. L. Goodhue, and R. L. Thompson, "Task-Technology Fit and Individual Performance", MIS Quarterly, 19, 1995, pp.213-236.

[9] C. Gan, H. Li, and Y. Liu, "Understanding mobile learning adoption in higher education", The Electronic Library, 35(5), 2017, pp.846-860.

[10] K. L. Hsiao, "What drives smartwatch adoption intention? Comparing Apple and non-Apple watche", Library Hi Tech, 35(1), 2017, pp.186-206.

[11] C. Tam, and T. Oliveira, "Understanding the impact of m-banking on individual performance: DeLone \& McLean and TTF perspective", Computers in Human Behavior, 61, 2016, pp.233-244. 
[12] A. Tarhini, M. El-Masri, M. Ali, and A. Serrano, "Extending the UTAUT model to understand the customers' acceptance and use of internet banking in Lebanon", Information Technology \& People, 29(4), 2016, pp.830-849.

[13] R. Kwai Fun Ip, and C. Wagner, "Weblogging: A study of social computing and its impact on organizations", Decision Support Systems, 45(2), 2008, pp.242-250.

[14]W. S. Lin, "Perceived fit and satisfaction on web learning performance: IS continuance intention and tasktechnology fit perspectives", International Journal of HumanComputer Studies, 70(7), 2012, pp.498-507.

[15] K. Y. Lin, "User communication behavior in mobile communication software", Online Information Review, 40(7), 2016, pp.1071-1089.

[16] D. L. Goodhue, and R.L. Thompson, "Task-Technology Fit and Individual Performance", MIS Quarterly, 19, 1995, pp.213-236.

[17] E. Deci, "Effects of externally mediated rewards on intrinsic motivation", Journal of Personality and Social Psychology, 18(1), 1971, pp. 105-115.

[18] H. W. Kim, H. C. Chan, and S. Gupta, "Value-based adoption of mobile internet: An empirical investigation", Decision Support Systems, 43(1), 2007, pp.111-126.

[19] F. Davis, "Perceived usefulness, perceived ease of use, and user acceptance of information technology", MIS Quarterly, 13(3), 1989, pp.319-340.

[20] K. Y. Lin, Y. T. Wang, and T. K. Huang. "What drives continued intention for mobile payment: An expectation cost benefit theory with habit", 51st Hawaii International Conference on System Sciences (HICSS 51), Big Island, Hawaii, USA, January 4-7, 2018.

[21] E. M. Rogers, Diffusion of Innovations, Fourth ed., New York: The Free Press, 1995.

[22] D. L.Goodhue, "Development and measurement validity of a task-technology fit instrument for user evaluations of information systems", Decision Sciences, 29(1), 1998, pp. 105-138.

[23] I. P. Tussyadiah, D. Wang, T. H. Jung, and M. C. tom Dieck, "Virtual reality, presence, and attitude change: Empirical evidence from tourism", Tourism Management, 66, 2018, pp.140-154.

[24] C. C. Chang, "Examining users intention to continue using social network games: A flow experience perspective", Telematics and Informatics, 30(4), 2013, pp. 311-321.

[25] T. P. Dong, N. C. Cheng, and Y. C. J. Wu, "A study of the social networking website service in digital content industries: The Facebook case in Taiwan", Computers in Human Behavior, 30(1), 2014, pp. 708-714.

[26] A. Bhattacherjee, "An empirical analysis of the antecedents of electronic commerce service continuance", Decision Support Systems, 32(2), 2001, pp.201-214.

[27] C. H. Hsiao, J. J. Chang, and K.Y. Tang, "Exploring the influential factors in continuance usage of mobile social APPs: Satisfaction, habit, and customer value perspectives", Telematics and Informatics, 33(2), 2016, pp. 342-355.

[28] J. C. C. Chen, "The crossroads of English language learners, task-based instruction, and 3D multi-user virtual learning in Second Life", Computers \& Education, 102(1), 2016, pp. 152-171.
[29] K. Y. Lin, and H. P. Lu, "Predicting mobile social network acceptance based on mobile value and social influence", Internet Research, 25(1), 2015, pp.107-13.

[30] N. Alkhater, R. Walters, and G. Wills, "An empirical study of factors influencing cloud adoption among private sector organizations", Telematics and Informatics, 35(1), 2018, pp. 38-54.

[31] H. M., Sabi F. M. E. Uzoka, K. Langmia, and F. Njeh, "Conceptualizing a model for adoption of cloud computing in education", International Journal of Information Management, 36(2), 2016, pp.183-191.

[32] W. L. Shiau, and P. Y. K. Chau, "Understanding behavioral intention to use a cloud computing classroom: A multiple model comparison approach", Information \& Management, 53(3), 2016, pp.355-365.

[33] X. Dong, and T. Wang, "Social tie formation in Chinese online social commerce: The role of IT affordances", International Journal of Information Management, 42, 2018, pp.49-64.

[34] V. L. Johnson, A. Kiser, R. Washington, and R. Torres, "Limitations to the rapid adoption of M-payment services: Understanding the impact of privacy risk on M-Payment services", Computers in Human Behavior, 79, 2018, pp.111122.

[35] D. Kim, and T. Ammeter, "Predicting personal information system adoption using an integrated diffusion model", Information \& Management, 51(4), 2014, pp.451464.

[36] W. I. Lee, S. Y. Cheng, and Y. T. Shih, "Effects among product attributes, involvement, word-of-mouth, and purchase intention in online shopping", Asia Pacific Management Review, 22(4), 2017, pp.223-229.

[37] A. A. Alalwan, "Investigating the impact of social media advertising features on customer purchase intention", International Journal of Information Management, 42, 2018, pp. 65-77.

[38] J. Fang, Z. Zhao, C. Wen, and R. Wang, "Design and performance attributes driving mobile travel application engagement", International Journal of Information Management, 37(4), 2017, pp.269-283.

[39] C. Fornell, and D. F. Larcker, "Evaluating structural equation models with unobservable variables and measurement error", Journal of Marketing Research, 18(1), 1981, pp. 39-50.

[40] J. C. Nunnally, Psychometric Theory, McGraw Hill, New York, NY, 1978.

[41] L. A. Hayduck, Structural equation modeling with LISREL. Baltimore, MD: Johns Hopkings University Press, 1987.

[42] J. Scott, "The measurement of information systems effectiveness: Evaluating a measuring instrument", In Proceedings of the Fifteenth International Conference on Information Systems, Vancouver, BC, 1991, pp.111-128.

[43] J. F. Hair, R. E. Anderson, R. L. Tatham, and W. C. Black, Multivariate data analysis. London: Prentice Hall, 1988.

[44] R. P. Bagozzi, and Y. Yi, "On the evaluation of structural equation models", Journal of Academy of Marking Science, 16(2), 1988, pp. 74-94. 